\title{
Conflating Time and Energy: Views from Older Adults in Lower Socioeconomic Status Areas on Physical Activity
}

DOI:

10.1123/japa.2017-0283

\section{Document Version}

Accepted author manuscript

Link to publication record in Manchester Research Explorer

\section{Citation for published version (APA):}

Devereux-Fitzgerald, A., Powell, R., \& French, D. (2017). Conflating Time and Energy: Views from Older Adults in Lower Socioeconomic Status Areas on Physical Activity. Journal of Aging and Physical Activity.

https://doi.org/10.1123/japa.2017-0283

\section{Published in:}

Journal of Aging and Physical Activity

\section{Citing this paper}

Please note that where the full-text provided on Manchester Research Explorer is the Author Accepted Manuscript or Proof version this may differ from the final Published version. If citing, it is advised that you check and use the publisher's definitive version.

\section{General rights}

Copyright and moral rights for the publications made accessible in the Research Explorer are retained by the authors and/or other copyright owners and it is a condition of accessing publications that users recognise and abide by the legal requirements associated with these rights.

\section{Takedown policy}

If you believe that this document breaches copyright please refer to the University of Manchester's Takedown Procedures [http://man.ac.uk/04Y6Bo] or contact uml.scholarlycommunications@manchester.ac.uk providing relevant details, so we can investigate your claim.

\section{OPEN ACCESS}


Running Head: CONFLATING TIME AND ENERGY IN PHYSICAL ACTIVITY

1

2

3

4

5

6

7

8

9

10

11

12

Conflating Time and Energy: Views from Older Adults

13

in Lower Socioeconomic Status Areas on Physical Activity

14 


\section{Abstract}

2 Perceptions of time and energy and their role in physical activity engagement were examined in older

3 adults living in lower SES areas. Semi-structured interviews were conducted with 19 participants aged

$4 \quad 67-94$ years. A thematic framework analysis identified four themes: Time is Energy (older adults

5 conflate time and energy in relation to physical activity); Reduced Day (engaging in activities outside a

6 certain timeframe is deemed unacceptable); Being Given Enough Time (need for time to socialise and

7 go at own pace); and Seasonal Impact (seasonal differences affecting access). Enjoyment appears to

8 mitigate the perceived energy drain and increase the capacity for physical activities for many.

9 Conflation of time and energy may explain observed discrepancies between older adults' actual and

10 perceived available time. Having locally-based physical activities means less time/energy is required

11 to attend, leaving more resources for physical activity itself. A limited availability of resources in lower

12 SES areas is therefore problematic.

13

14 Abstract Word Count: 150/150

15

16 Keywords: acceptability; enjoyment; deprivation; ageing; qualitative 


\section{Introduction}

Up to $87 \%$ of males and $92 \%$ of females over the age of 65 years in England do not meet current guidelines of 150 minutes of moderate physical activity and two sessions of strength training per week (Scholes \& Mindell, 2013). This is despite evidence of multiple physical, psychological and

5 social benefits of physical activity for older adults, such as lowered risk of chronic illness and mortality,

6 improved mood, increased quality of life, and maintenance of cognitive and physical function leading

7 to retention of independence (Rejeski \& Mihalko, 2001; UK Department of Health, 2011). Those living in a deprived or lower socioeconomic status (SES) area are twice as likely to be inactive as those in higher SES areas (Public Health England, 2014). Deprivation has been defined as a lack of resources resulting in unmet basic needs, measured across several socioeconomic factors e.g.

11 income, employment, health, education, housing, access to local services, local environment, safety

12 and crime (Department for Communities and Local Government (DCLG), 2011). Individual SES is

13 commonly measured on factors such as education, occupation and income. Low individual SES

14 throughout the life course has been shown as a determinant of low physical activity in older adults

15 (Hillsdon, Lawlor, Ebrahim, \& Morris, 2008).

In addition to individual SES factors, living in a more socioeconomically deprived area in older

17 age is also an independent risk factor of lower physical activity levels for older people, regardless of previous individual SES (Hillsdon et al., 2008). The disparity in physical activity levels for older adults according to deprivation of the area in which they live has been explained as being due to both environmental aspects (e.g. lack of safe, pleasant amenities) and social aspects (e.g. feeling of not

21 fitting in) of more deprived areas (Annear, Cushman \& Gidlow, 2009). Budgetary constraints

22 impacting provision of physical activity programmes in deprived areas may decrease opportunities for

23 engagement in physical activity by older adults in such areas (King, 2001). It has also been proposed

24 that lower levels of physical activity may have more to do with individual characteristics of those living 
1 in deprived areas, such as being older, having lower physical function, higher body mass index and a

2 reduced tendency to leave the home (Fox et al., 2011). Alongside deprivation, low perceived available time and feelings of being rushed appear to

4 impact negatively on physical activity levels. This effect worsens the longer the lack of resources is

5 experienced (Venn \& Strazdins, 2017). Some older adults believe they may have more time and

6 energy to engage in physical activity when anticipating retirement (McDonald, O'Brien, White \&

7 Sniehotta, 2015). However, for many older adults this perception does not hold through into actual retirement, with lack of time still a commonly cited barrier to engaging in physical activity in older age, whether directly stated (e.g. Justine, Azizan, Hassan, Salleh, \& Manaf, 2013) or in reference to competing priorities (Franco et al., 2015; McGowan, Devereux-Fitzgerald, Powell \& French, 2017).

11 Whilst some older adults continue to work or have caring commitments, many do not, and therefore it

12 begs consideration whether older adults are experiencing an actual lack of time, or whether

13 something else is triggering this perception.

Physical activity promotion for older adults is often focused on health risks or long-term health outcomes (e.g. Public Health England, 2014; UK Department of Health, 2011). However, interventions to encourage physical activity in older adults using information on risks or consequences of behaviour

17 to encourage physical activity lack efficacy (O'Brien et al., 2015). This may be due to older adults

18 perceiving such risk related-health information as negative or not salient (McGowan et al., 2017). The

19 lack of efficacy of previous physical activity interventions may be explained by Socioemotional

20 Selectivity Theory (SST) in which "the perception of time plays a fundamental role in the selection and

21 pursuit of social goals" (Carstensen, Isaacowitz, \& Charles, 1999, p. 165) with those having less time

22 (e.g. reduced lifespan in older age) protecting this valued resource by focusing more on emotionally

23 satisfying goals. To maintain emotional balance, and not waste time, older adults may therefore be

24 more motivated to ignore negative information (Löckenhoff \& Carstensen, 2004). Focusing on 
negative health risks in physical activity promotion may also be damaging to self-identity in older age,

2 as it emphasises decline as an inevitable part of ageing (Phoenix \& Orr, 2015).

A more promising approach to physical activity promotion relates to the observation that older adults experience numerous types of enjoyment around physical activity: social interaction,

5 intrinsic fun, sense of achievement, increased confidence (Devereux-Fitzgerald, Powell, Dewhurst \&

6 French, 2016); structure/routine, sense of purpose, pleasure of total immersion in an activity (Phoenix

7 \& Orr, 2014). Csikszentmihalyi (1990) sees enjoyment as pleasure coupled with a sense of achievement, which leads one to an optimal flow state. When in this flow state, enjoyment appears to impact on perception of time, (e.g. perceiving only minutes to have passed when hours have, or vice versa), in line with the saying 'time flies when you are having fun'. The importance of enjoyment was discussed in two recent meta-syntheses of qualitative studies, where physical activity was deemed more acceptable and relevant to older adults when perceived as enjoyable and social (Devereux-Fitzgerald et al., 2016; McGowan et al., 2017). By contrast, most interventions to date have not targeted these factors (French, Olander, Chisholm, \& McSharry, 2014).

A key limitation of the primary qualitative studies identified in the meta-syntheses on acceptability of physical activity in older adults is that there is little data from older adults within low SES environments. To develop interventions or services that are engaging to older adults within low SES populations, we need to ascertain which factors affect older adults' acceptability of physical activity in such areas. To address this issue, we have undertaken a multi-perspective research project on acceptability of physical activity to older adults living within lower SES areas. The aim of this project was to explore factors relating to acceptability from the perspectives of those older adults living in lower SES areas, trainers/group leaders delivering physical activities within these areas, and physical activity providers who organise such activities. The present paper focuses on a set of findings discovered in older adults' interviews during the larger research project which merited further analysis in its own right: the conflation of time and energy relating to their engagement in physical activity. 
1 Although previous research has looked at the impact perceived time can have on being physically

2 active (e.g. Venn \& Strazdins, 2017; Justine et al., 2013), such research has considered time at face

3 value. The aim of the present paper was to address this lack of in-depth analysis by exploring different

4 perceptions of time and energy around physical activity in older adults, and any factors which

$5 \quad$ impacted these perceptions in lower SES environments.

\section{Method}

Participants. Adults were eligible if aged 65 years or older, lived independently in identified lower SES areas, had sufficient English language skills to be interviewed and who could walk continuously for 10 minutes unassisted by another person. Participants were recruited from council wards (local government areas) of Manchester (UK) that scored in the highest $50 \%$ across the city in

11 terms of deprivation specifically for older adults. Actual ward deprivation figures ranged from $38.5 \%$ -

$1254.8 \%$ of older adults living in poverty, compared to the English national average of $18.1 \%$ (DCLG,

13 2011). Deprivation figures were based on factors including income, crime risk, access to local

14 amenities, and living environment (DCLG, 2011). Purposive sampling was used to ensure a broad

15 variation in the sample in terms of residential area, age and activity levels (see Table 1) and allowed

16 for a wider range of views to be gathered than random sampling may have produced. After initial

17 interviews, males and immigrant participants were particularly sought, as these proved less accessible 18 at initial recruitment drives.

Procedure. Institutional ethical approval was granted. Recruitment was publicised via local government and research newsletters, libraries, age-related charities, and a snowballing approach.

21 The first author attended coffee mornings, library groups, physical activity sessions and craft groups

22 for older adults, to discuss the research with them and promote recruitment. Eligibility was

23 established using short screening questions regarding walking ability and residence. The first author

24 then conducted private face-to-face interviews, at a time and place convenient to participants, with no financial remuneration beyond travel expenses. Informed consent was taken in person at the start 
1 of the interview session. A pre-interview questionnaire was completed with participants for

2 demographic and background data. Data from previous interviews were considered when

3 undertaking subsequent interviews so that emerging topics could be addressed. Interviews lasted

4 between 31 and 77 minutes (median 54 minutes) and were audio-recorded.

5 Materials. The pre-interview questionnaire captured demographic data, perceived fall risk

6 and self-reported physical activity levels (based on amount of time regularly spent per week on

7 physical activities the participants categorised as light, moderate or vigorous). Participants were

8 deemed active if they met the recommended guideline of 150 minutes of moderate physical activity

9 per week, and inactive for those not meeting this guideline. The interview schedule included topics on

10 how participants felt about physical activity, how they would describe themselves in terms of physical

11 activity levels, how they would feel about increasing physical activity, what they did/did not enjoy

12 about physical activity, benefits or concerns around physical activity, local physical activity provision,

13 and how physical activity had/could become an acceptable part of older adults' lives (see

14 supplementary material).

Analysis: Data were analysed using Thematic Analysis (Braun \& Clarke, 2006) utilising indexing and matrix principles of the Framework Approach (Ritchie \& Spencer, 1994) to permit a

17 comprehensive analysis with transparent, accessible organization of the data. Interviews were

18 transcribed verbatim, read and re-read to achieve familiarisation, and relevant topics were identified

19 in relation to the research question. Initial codes were systematically generated and collated into a

20 hierarchical thematic framework of potential themes and sub-themes, with both latent and extant

21 themes being explored. All instances of themes were re-considered, with themes merged or split as

22 necessary. The data were indexed and framework matrices were constructed to enable thematic and

23 case-based analysis, and to assist with identification of linkage between same or different phenomena

24 (Spencer, Ritchie, O'Connor, Morrell \& Ormston, 2014). 


\section{Results}

Of 25 older adults who expressed interest, 19 participated. Of the six remaining candidates

3

4

5

6

7

8

9 two were ineligible due to residential location, two withdrew due to ill health and two declined to take part without any reason given. The 19 participants (see Table 1 ) were aged 67-94 years (15 female, 4 male) and represented eight council wards across all areas of the city of Manchester: North Manchester ( $n=4)$; East Manchester $(n=4)$; South Central Manchester $(n=5)$; South Manchester $(n=6)$. One participant identified as British Pakistani; four as White Irish, and 14 as White British. Two participants were educated to PhD level, five had attended further education, seven completed high school, and five had some high schooling. Of the married participants ( $n=7)$, two married couples took part (interviewed separately). The non-married participants were widowed $(n=6)$, divorced $(n=3)$ and single $(n=3)$, with ten living alone, whilst the remaining two lived with family members. Three of the participants had full-time caring responsibilities for a family member who lived with them. Some participants had regular weekly care of grandchildren $(n=4)$, but the majority reported only social visits with no caring responsibilities $(n=15)$. Most participants had no work-related commitments $(n=12)$, however seven undertook voluntary work with a variety of hours per week: $10+$ hours $(n=2), 4-6$ hours $(n=3)$, and 2 hours $(n=2)$. Most participants did not have their own transport ( $n=15)$; the remaining participants ( $n=4)$ were married and shared use of household cars with their spouse (three cars in total in the sample). Participants were categorized as active $(n=8)$ or inactive $(n=11)$ based on self-reported physical activity (pre-interview questionnaires). Some participants also met guidelines on flexibility $(n=6)$, of whom one was inactive and one was male. One male and one female participant met the recommendations on strength training two days per week. Ten participants did not feel at risk for falls; the remaining nine did but only in certain circumstances (e.g. without walking stick; in icy/wet weather). 
Themes. The thematic analysis produced four themes which illustrate the different

perceptions of time for older adults in lower SES areas in relation to physical activity: Time is Energy;

Reduced Day; Being Given Enough Time; and Seasonal Impact. Quotes are denoted by italics with participant age, gender and activity status given. Pseudonyms are used to preserve participant anonymity.

\section{Time is Energy}

Some participants referred to a lack of time for physical activity, despite most participants having indicated that there was time available in their schedule due to low working or caring commitments: "It's having the time, isn't it [laughs]" (Shirley, F, 70, inactive). Often time and energy seemed to be conflated, or merged into one concept, particularly when discussing time spent getting to and from activities "I have to get there... and that's walking and on buses... you know, I want something easier really, within easy reach" (Claire, F, 67, inactive). Time and energy were viewed as precious, limited resources which older adults did not wish to waste on physical activity that they found irrelevant or unenjoyable, or on getting to their preferred activity: "I would tap dance all day, but I don't feel as if I'd want to walk that far to get TO it [laughing]... I just want to get in there and start doing it. I'm not a walker" (Olive, F, 70, active). However, when an enjoyable activity was anticipated, this offset the added energy expenditure of getting ready "You're up and out, and you don't care" (Sally, F, 78, active), making the whole concept more acceptable: "[then] I enjoy the whole activity of, 'Right it's time to get ready now, I'm going to have my shower' [] knowing I'm going to be doing something that I enjoy" (Olive, F, 70, active).

Linked to this was the availability of local and individual resources. Most participants did not own cars, but this made a substantial difference in terms of time and energy expenditure for those that did, as they did not have to consider the journey to activities. Those without a car who did not enjoy active travel, were less mobile, or lacked funds, had much higher energy and time expenditure involved in attending activities. This was particularly notable when local venues closed down and 
1 previously enjoyed physical activities became unacceptable due to the time and energy required for

2 travel:

3 "I used to go swimming quite a lot, but they've closed the [local] baths...so it means now ... you've

4 got to start getting buses to, you know, leisure centres and, so it's not always easy when you're

5 older to mess about... I'd have to get two buses from here" (Claire, F, 67, inactive).

The more active older adults felt they had a higher level of energy "I don't FEEL like a pensioner, you know, because l've got so much energy and I'm always on the go and I'm always looking for new things to do" (Olive, F, 70, active). This was viewed as a sign of youth and a direct result of being physically active "I just feel a bit younger than what I am. Probably it's because I'm doing all these exercises" (Julie, F, 72, active). There was also a fear of losing this energy and vitality

11 through time spent being inactive: "as a retired person you know it's very easy to sit here at home and watch the TV... but I don't do that because l've seen other people do that and it leads to all kinds of things... So I can see the results of not being physically active" (Sam, M, 67, active). Inactive participants seemed more aware of their energy expenditure, with forms of physical activity they classed as exercise deemed to take more energy compared with more social physical

17 activities: "How can I put it, more energy, ...type of thing, isn't it, swimming than dancing" (Shirley, F, 1870 , inactive). The least active older adults also seemed to perceive a higher energy and time expenditure requirement of light or moderate intensity activities such as walking to the local shop, e.g. perceiving locations to be further away than they were "it's about quarter of a mile to the shops, it's about half a mile to [activity venue]" (Ben, $M, 74$, inactive) (actual distances 0.1 mile and 0.3 miles respectively). This may be due to the amount of time it took those with low physical fitness to reach

23 their destination. Health problems could indeed mean that they were expending more energy than a 24 fitter person to engage in basic tasks. 
For some, time and energy spent working had been an obstacle to being physically active for leisure, and they relished this freeing up of resources in retirement: "I become [sic] a new man! I started doing exercise [laughing]. I think the fact that I was retired... the work got in the way of the exercise" (Kevin, $M, 71$, active). Some missed the routine of work, while others who had held physically demanding jobs missed being physically active, replacing this energy output in retirement with regular physical activity: "I've done more now since I've retired than l've ever done in my life" (Julie, F, 72, active). However, many inactive older adults who previously held active jobs only related physical activity to hard work, or wear and tear. Some even expressed doubts that it could benefit their health, and therefore wasn't worth spending their limited time and energy on: "I think at times it is a little bit overstated as far as medical's [sic] concerned"' (Ben, M, 74, inactive). distracted from the physical aspect of an activity, especially limitations of health conditions (e.g. pain, breathlessness). Distractions could be: combining physical activity with unrelated everyday tasks: "even when I'm ironing, I'm [moving]... my feet" (Liz, F, 74, active); having an enjoyable separate purpose: "Don't just walk, give them something to do at the same time" (Olive, F, 70, active); or social enjoyment: "You forget what's wrong with you when you've got a crowd of people" (Grace, F, 94,

17 inactive). Older adults reported spending longer engaged in higher energy physical activities when enjoying the company of others than when alone. For example, one participant found he needed to rest after 10 minutes when gardening at home: "if I do any digging, over exerting myself, for about ten minutes or so, I then have to sit down for a few minutes" (Ben, $M, 74$, inactive), whereas with his

21 gardening club this duration was doubled: "all of us are the same, you know, after twenty minutes or

22 so we'll all have a sit down" (Ben, M, 74, inactive). However, some older adults found it was intrinsic enjoyment of the physical activity itself that altered their perception of time: "I'm very focused when

24 I'm on the machines. It's fantastic... I say, 'I am lost at the gym.' I'm living in the present moment there" (Al, $M, 77$, active). 


\section{Reduced Day}

Low acceptability of multiple activities in one day was apparent for many participants, whether these activities were physical or sedentary: "when you get older you can only do like one thing in a day" (Claire, $F, 67$, inactive). This led to a reduction in perceived availability of time for further activities, perhaps due to time and energy being conflated, and their limited resources being needed for basic chores and getting to the activity, as well as the activity itself:

"by the time you've done what you wanted to do here [at home] in the morning, and then we go to the [sedentary activity], and then by the time we come home we get our tea and so that's the day gone. And when I go for the [physical activity] on a Tuesday and I'm there from about half past nine til maybe half past twelve, and then by the time we come home and have a bit of lunch and there's another day gone" (Ben, M, 74, inactive).

For some, particularly inactive participants, the reduced day seemed to stem from a lack of flexibility towards changing schedules, even to accommodate much loved physical activities, such as this lady's dance class: "Well it was a bit inconvenient on a Saturday morning, cos I usually do shopping" (Claire, F, 67, inactive). Weekends seemed to be viewed differently to the rest of the week for many, even in retirement: "My Saturday is my time" (Kath, F, 77, inactive). Conversely, some of the active participants were willing to change their schedules to accommodate physical activity "Some of these [new classes] coincide with our dinner time in the evenings. So that's a matter of moving the dinner time and say, 'We're going'"' (Diana, F, 71, active). Maintaining emotional balance by protecting enjoyed activities in light of limited resources was evident, whether these activities were physical or not: "I might do something at the expense of something else that I want to do... you've got to get that balance right, where you're happy to do that amount and happy to do that non-exercise bit" (Sam, M, 67, active). 
For those who were open to engaging in multiple activities per day, there was not always enough time to get from one activity to another without their own transport, as activities for older adults also tended to be provided within a reduced window of time: "But it's so awkward for us. We don't finish till twelve o'clock and they start at one...and you have to get the bus to both places" (Sally, F, 78, active). Lack of local amenities and public transport issues also fed into this, as earlier activities which needed to be reached by bus could not be engaged in freely: "daytime [activities] starts at half nine, quarter to ten, again pensioners we'd have to pay $f 2$ odd for that bus. If it was put at a time where we could get on the half past nine bus, it wouldn't cost us" (Linda, F, 68, inactive).

More active participants seemed happy to engage in walking as active transport to overcome this, although this was related to an individual's mobility, enjoyment of walking, and financial situation: "it costs me $f 2$ to go from here to [local venue] if I go before half past nine in the morning, so I won't, I just walk [laughing] cos I won't pay the money" (Sally, F, 78, active). the crowds, especially children, whether cycling in the park: "It's the safest time to go because there's nobody around... it's not like if you go in the afternoon there's kids and everything running out in front

17 of you" (Diana, F, 71, active); or walking around town: "half ten in the morning I'm usually out there... because it gets crowded in the afternoon. It's more young people isn't it" (Susan, F, 80, inactive). Active participants noted that older adults were generally in the minority later in the day, as noted by this regular gym user: "the old people had gone by 4 o'clock or 5 o'clock" (Al, M, 77, active). dancing in local community centres: "Cos there's no alcohol involved, you know. That would appeal" 
1 taxis. Those without such resources spoke of the difficulties in engaging in activities in the evenings or

2 night times: "I'd love to go to aqua fit... it's at half eight at night... so everything's a taxi. Well I don't

3 have the money to get taxis" (Linda, F, 68, inactive). Many older adults with limited resources found

4 their day constrained by factors beyond their control rather than by choice, which was not understood

5 by others with more resources: "they're saying 'You should go' but it's all people sitting with cars"

6 (Linda, F, 68, inactive). Daylight was an important consideration, particularly for those with reduced

7 mobility and could explain such reticence in engagement later in the day for some: "how do I get there

8 and how do I get back... Trying to cross the road in a [mobility] scooter, cos they just don't care... No, I

9 don't want to go out at night time and when it goes dark" (Jo, F, 69, inactive). Others were fearful of

10 crime in their neighbourhood after dark "you can't go out in the evening and come back on your own...

11 you've got to be careful" (Julie, F, 72, active), particularly if waiting around for transport "[it's a] bit of

12 a rough area up there, if you know what I mean. So you don't want to be stood outside" (Linda, F, 68,

13 inactive).

14 Being given enough time

The perception of having enough time within physical activities was important for numerous

reasons. Perceiving the need to hurry to an activity whether because of stringent timekeeping or

17 complicated personal schedules lowered acceptability: "I can't do rushing around. It just gets me all

18 on edge. I just like to be able to take my time at things" (Claire, F, 67, inactive). Older adults needed

19 to feel at ease within structured physical activities, so that they would still attend if they were running

20 late, rather than miss the class:

21 "Everybody laughs... there's no, 'Be there on time', or restrictions... and you think 'Oh, I'm gonna be

22 late', you don't think 'Oh I won't go'. You go... cos you want to go and it's not gonna interrupt the

23 class or anything" (Sara, F, 74, inactive). 
What may be perceived by many as ample time to engage in physical activity does not appear

2 that way to many older adults: "then you've only got from two [pm] til about four [pm] or, you know,

3 to do something and it's... it's not really enough time" (Claire, F, 67, inactive). Not feeling they can

4 comfortably engage in physical activity within such a timeframe may be due to many factors: the time

5 and energy expenditure involved in getting ready and travelling to an activity; the need to not feel

6 rushed; the possible foreshortening of their day; low acceptability of multiple tasks per day; and

7 needing time to socialise.

Time and encouragement to socialise around an activity was valued by many. One participant

9 now has twice weekly lunch sessions after class with his exercise classmates: "Well they said to me

10 'Why don't you just stay? Why do you go home?'” (Kevin, $M, 71$, active). A walking group

11 accommodated all members by ensuring even the slowest had time to stop for tea and cake without

12 rushing: "But [friend] and I were well behind. And we just took our time and caught them up" (Sally, F,

1378 , active). Unreliable community transportation (i.e. free door-to-door services for eligible residents)

14 often encroached on physical activities and any possibility of socialising: "well they never get the

15 chance to socialise after. They always come picking them up too early" (Claire, F, 67, inactive). Such

16 services seemed notorious for leaving without their pick-up, and several older adults reported leaving

17 their activities before their scheduled finish for fear of being stranded, leaving them standing outside,

18 often alone: "You've got half an hour waiting, whatever the weather, cos if you're inside... he goes"

19 (Linda, F, 68, inactive).

20 Seasonal Impact

Seasonal differences in time and energy perceptions, and the impact these perceptions had on

22 engagement in physical activity, were apparent. Many older adults in low SES neighbourhoods found

23 it easier to access physical activities during the lighter evenings of summer, but not all older adults

24 found the warmer weather conducive to being physically active: "I wouldn't over exert in the heat, cos 
1 I think that's silly" (Pam, F, 72, inactive). Some however felt it took less time and energy to prepare for 2 physical activity in the warmer months:

"Well you're not waiting in the cold for buses and things like that... You're not wondering if you put two jerseys on that are too heavy or too thick and you can't do the Tai Chi. It's summer you put light things, $t$-shirts and you're away... Much easier in the summer to go to these classes" (Sara, F, 74, inactive).

Certain physical activities (e.g. walking, swimming) seemed less appealing in the coldest months for some, and many reported classes and groups taking an extended break around December/January. However, some older adults were disappointed when services were not reinstated more quickly, as one participant noted in May: "[the walking group] finished like for the winter, and they've not got it sorted out yet again" (Julie, F, 72, active). Making small accommodations in different seasons increased acceptability, such as exercising in a warmer room in winter: "they would want it cosy and warm in winter" (Linda, F, 68, inactive) and being understanding of weather-related travel issues: "it's got to be very, very relaxed in the winter class, where you can just stroll in if you're late" (Sara, F, 74, inactive). The increased depletion of energy just to get to physical activities was a major concern for many: "...walking in the rain. It takes it out of you" (Sara, F, 74, inactive); and even the most active struggled: "normally it takes me 15 minutes and it took me an hour [walking in the snow] ...I never attempted it again" (Sally, F, 78, active).

The impact of closed local facilities in low SES areas was even more keenly felt by those without cars throughout the year. In the summer, those who relied on other older adult friends for transport or company at physical activities were less likely to attend if these friends went away for prolonged periods: "She goes [abroad] quite a lot you see, so she wasn't around and I'd say, "If she's not going, I won't bother" you know" (Mo, F, 89, inactive). Whereas in the winter, inclement weather magnified public transport issues: "that's a big issue, really... waiting around for buses, especially in the winter if 
1 your hair's wet" (Claire, F, 67, inactive). Weather seemed less of a barrier for active older adults on

2 direct bus routes or with cars "I've gone in when it's been snowing and everything and ice" (Kevin, M, 371 , active).

4

\section{Discussion}

This study found that when older adults spoke of 'not having time' to be physically active they often seemed to be referring more to the perceived energy expenditure required to engage in physical activity, which included getting ready, and travelling to and from activities. For those who engaged regularly in enjoyed physical activities, anticipation of attending often seemed to offset negative perceptions of such energy expenditure. Lack of local amenities in low SES areas was often compounded by a lack of individual resources, such as own transport or taxi fares. This made engaging in physical activities outside of the home more onerous, and therefore less acceptable, than for those with such resources. This was particularly apparent during inclement weather, when further energy expenditure was required merely to attend an activity, and on dark nights when fears for safety were an issue. Physical activity in the evening tended therefore to be pursued only by those with their own car or sufficient finances for taxis, despite those without such resources professing an interest. Many, particularly inactive, older adults viewed multiple activities per day as unacceptable. Basic chores were also seen as a drain on time and energy for the less active, leaving them with fewer perceived resources than active older adults. However, losing oneself in a physical activity, whether through intrinsic enjoyment or the enjoyment and distraction of the social nature of the group, seemed to enable even the most inactive to increase their capacity for physical activity. A lack of flexibility and rigidity of thinking was more apparent with some inactive older adults, which meant that activities had to occur on set days or times to be acceptable, even giving up desired physical activities if they fell outside these times. Having a relaxed, sociable atmosphere within organized physical activities encouraged attendance, particularly when tackling weather or transport difficulties. Being encouraged to socialize within and beyond classes or groups was highly valued, and this added 
1 to the enjoyment and increased acceptability of regular physical activity for many. However,

2 unreliable transport services severely constrained such socializing, or even completing an activity for

3 some, meaning those without personal resources were again negatively impacted.

Strengths and limitations of study. This study addresses the lack of data in the literature on

5 acceptability of physical activity from older adults living in deprived areas. The study took place in

6 Manchester, a city ranked third highest for deprivation in England (DCLG, 2011). Recruitment focused on areas with higher deprivation specifically for older adults. Recruitment was primarily achieved by going into communities to talk with older adults about the research. Purposive sampling was used to ensure that active and inactive older adults' views were gathered. Activity levels were derived from data given over multiple questions, using recommended guidelines for activity levels, rather than older

11 adults self-identifying as active or inactive. However, the self-report of this data, with the problems of retrospective reliability and social desirability, is noted as a weakness. The sample consisted mainly of white British and Irish females, so is not fully representative of the wider older adult population.

Although males and ethnic minorities were specifically sought, they were difficult to access within the study timeframe. As this study took place within a city, there may be unidentified issues relating to older adults and physical activity within deprived rural areas.

Relationship to literature. Our findings that a perceived lack of time is a substantial barrier to physical activity for older adults in lower SES environments is in line with previous studies in the general adult population (Venn \& Strazdins, 2017) and in middle-aged and older adults (Justine et al., 2013; Franco et al., 2015). Further, our findings support those of Venn and Strazdins (2017), in that perceptions of being time poor seemed compounded by a lack of financial resources. However, in contrast to previous studies, our findings suggest that it is not simply time that is a factor for older adults, but rather a combination of time and energy, which were often conflated by participants. This could explain the disparity between perceived and actual free time older adults had in which to be 
1 work on the impact of reduced amenities in low SES environment on older adults' levels of physical

2 activity (Annear, Cushman \& Gidlow, 2009; King, 1999; Fox et al., 2011) but expand on this by

3 identifying explanatory factors. Most participants in the current study spoke of issues attending

4 physical activities outside the home, with very few older adults commenting on incidental physical

5 activity within the home or neighbourhood. Participants experienced a lack of local and individual

6 resources which increased the time/energy required just to get to a venue. This lowered the

7 acceptability of engaging in physical activity in low SES areas, as many older adults perceived this extra

8 expenditure to be beyond their capabilities. Although some older adults expressed a desire to be

9 more active, few engaged in specific physical activity within the home or local neighbourhood, even

10 though this would remove some of the time/energy barriers. This could suggest that older adults

11 wanted something more than just the physical activity itself, or that they do not conceptualise

12 incidental activities in the home and local neighbourhood as relevant to physical activity. Increased

13 time/energy expenditure also negatively impacted the acceptability of multiple activities in a day,

14 whether physical or not, as the energy required to get to any activity was perceived as a substantial

15 drain on limited resources. Those with greater individual resources (e.g. cars/money for transport)

16 experienced reduced expenditure and easier accessibility as most environmental issues such as lack of

17 local amenities, safety, and weather were negated. If time and energy are conflated, by both

18 participants and researchers, interventions may fail to adequately address the factors responsible for

19 older adults' low engagement levels in physical activity.

In line with previous studies (Jallinoja, Pajari \& Absetz, 2009; McGowan et al., 2017), many of 
1 the activity itself, to the environment and the habit of it recurring. Our results suggest that having

2 both social and physical needs met within the same time/energy expenditure meant that physical

3 activity was not abandoned in favour of more emotionally satisfying social interaction when faced

4 with limited resources, in agreement with SST (Carstensen et al., 1999). For the majority of our

5 participants, social interaction increased their perceived enjoyment and seemingly increased the

6 ability of even the most inactive to increase the time they were able and willing to be physically active.

7 This alteration in perception of time is in common with Csikszentmihalyi's (1990) flow state which is

8 achieved when individuals are immersed in enjoyable, achievable activities.

Implications for practice. Basing physical activities locally in low SES areas, and aligning them

with free fare periods on public transport, could help reduce the time and energy expenditure

11 required to access them. Training is needed within community door-to-door transport services on the

12 importance of giving older adults enough time for completion of activities and socialising, and on

13 providing reliable evening coverage, when barriers are greater. Providing physical activities in

14 neighbouring areas at different times may help accommodate those with less flexible schedules, as

15 well as increasing older adults' social circles, giving them more choice and perhaps increasing the

16 acceptable window of time for activities to take place, so long as they are easily accessed. Physical

17 activity services could be provided throughout the year, with seasonal accommodations made rather

18 than taking a hiatus (e.g. walking indoors during winter, perhaps at art galleries, shopping centres,

19 etc). Raising awareness of increased energy through being regularly physically active, rather than

20 focusing on negative health risk information may encourage engagement. Local provision of social

21 physical activities (e.g. dancing, walking groups), promoted as fun, relaxing pastimes, may help to

22 dispel the perception that physical activity needs to be hard work, undertaken at the expense of

23 leisure time.

Implications for research. To establish the role that perceived available energy plays in 
instance, longitudinal research could examine differences in perceived energy before, during and after physical activity interventions with older adults (alongside measures of perceived and actual time passed), using both quantitative and qualitative assessments. Becoming aware of the hypothesised increased energy could increase older adults' acceptability of physical activity as first-hand experience

5 has high value to them (Devereux-Fitzgerald et al., 2016). Exploring the acceptability of accumulation

6 of incidental physical activity through everyday activities (e.g. heavy housework, walking to shops) may be useful for those who do not perceive they have the resources to engage in organised external physical activity and are not looking to increase their social interaction. As emotional regulation is a primary goal for older adults according to SST (Carstensen et al., 1999) exploring energy and affect in relation to lower intensity social activities typically preferred by many older adults could be beneficial,

11 as less vigorous physical activity has been related to higher affect and adherence in the general adult population (Ekkekakis, Parfitt \& Petruzzello, 2011). The importance of self-efficacy in physical activity is well known, and the perception of having enough time to go at a comfortable pace is integral to this confidence in ability, however perceived energy also needs to be explored as a possible related factor. As energy is an internal resource, it may be an important self-sufficient factor in maintenance of physical activity for older adults in lower SES areas who have limited external resources (e.g.

17 transport, money). Further investigation into the perception of utilising less resources (e.g. altered time perception) when in a flow state, and whether this also includes energy expenditure, could be pertinent to older adults with limited resources.

Conclusion. Conflation of time and energy may be masking some factors of older adults' acceptability of physical activity. Enjoyment in many forms appears to increase older adults' perceived

22 available time and energy to engage in physical activity, and to offset negative perceptions of it being

23 a drain on limited resources. Increased acceptability of physical activity in low SES areas may be more

24 broadly achieved by reducing older adults' time and energy expenditure to attend activities, thereby

25 allowing them enough perceived time and energy to engage in the physical activity itself. 


\section{References}

Annear, M.J., Cushman, G., \& Gidlow, B. (2009). Leisure time physical activity differences among older adults from diverse socioeconomic neighborhoods. Health \& Place, 15, 482-490.

Braun, V., \& Clarke, V., (2006). Using thematic analysis in psychology. Qualitative Research in Psychology, 3, 77-101.

Carstensen, C.E., Isaacowitz, D.M., \& Charles, S.T. (1999). Taking time seriously: A theory of socioemotional selectivity. American Psychologist, 54(3), 165-181.

Csikszentmihalyi, M. (1990). Flow: The psychology of optimal experience. New York: Harper Collins.

Department for Communities and Local Government. (2011). English Indices of Deprivation 2010. Retrieved October 20, 2014 from https://www.gov.uk/government/statistics/english-indices-ofdeprivation-2010

Devereux-Fitzgerald, A., Powell, R., Dewhurst, A., \& French, D.P. (2016). The acceptability of physical activity interventions to older adults: A systematic review and meta-synthesis. Social Science \& Medicine, 158, 14-23.

Ekkekakis, P., Parfitt, G., \& Petruzzello, S.J. (2011). The pleasure and displeasure people feel when they exercise at different intensities. Sports Medicine, 41(8), 641-671

Fox, K.R., Hillsdon, M., Sharp, D., Cooper, A.R., Coulson, J.C., Davis, M., et al. (2011). Neighbourhood deprivation and physical activity in UK older adults. Health \& Place, 17, 633-640.

Franco, M.R., Tong, A., Howard, K., Sherrington, C., Ferreira, P.H., Pinto, R.Z., \& Ferreira, M.L. (2015). Older people's perspectives on participation in physical activity: a systematic review and thematic synthesis of qualitative literature. British Journal of Sports Medicine, 49, 1268-1276.

French, D.P., Olander, E.K., Chisolm, A., \& McSharry, J. (2014). Which behaviour change techniques are most effective at increasing older adults' self-efficacy and physical activity behaviour? A systematic review. Annals of Behavioral Medicine, 48, 225-234.

Hillsdon, M., Lawlor, D.A., Ebrahim, S., \& Morris, J.N. (2008). Physical activity in older women: Associations with area deprivation and with socioeconomic position over the life course: Observations in the British Women's Heart and Health Study. Journal of Epidemiology \& Community Health, 62, 344-350.

Jallinoja, P., Pajari, P., \& Absetz, P. (2009). Negotiated pleasure in health-seeking lifestyles of participants of a health promoting intervention. Health, 14(2), 1-16.

Justine, M., Azizan, A., Hassan, V., Salleh, Z., \& Manaf, H. (2013). Barriers to participation in physical activity and exercise among middle-aged and elderly individuals. Singapore Medical Journal, 54(10), 581-586. 
King, A.C. (2001). Interventions to promote physical activity by older adults. Journals of Gerontology, SERIES A, 56A (Special Issue II), 36-46.

Löckenhoff, C.E., \& Carstensen, L.L. (2004). Socioemotional Selectivity Theory, Aging and Health: The increasingly delicate balance between regulating emotions and making tough choices. Journal of Personality, 72(6), 1395-1424.

McDonald, S., O'Brien, N., White, M., \& Sniehotta, F.F. (2015). Changes in physical activity during the retirement transition: A theory-based qualitative interview study. International Journal of Behavioral Nutrition and Physical Activity, 12:25, doi: 10.1186/s12966-015-0186-4

McGowan, L., Devereux-Fitzgerald, A., Powell, R., \& French, D.P. (2017). How acceptable do older adults find the concept of being physically active? A systematic review and meta-synthesis, International Review of Sport and Exercise Psychology, doi: 10.1080/1750984X.2016.1272705

O'Brien, N., McDonald, S., Araújo-Soares, V., Lara, J., Errington, L., Godfrey, A., Meyer, T. D., Rochester, L., Mathers, J. C., White, M., \& Sniehotta, F. F. (2015). The features of interventions associated with long-term effectiveness of physical activity interventions in adults aged 55 to 70 years: A systematic review and meta-analysis. Health Psychology Review, 9(4), 417-433.

Phoenix, C., \& Orr, N. (2014). Pleasure: A forgotten dimension of physical activity in older age. Social Science \& Medicine, 115, 94-102.

Phoenix, C., \& Orr, N. (2015). The multidimensionality of pleasure in later life. In E. Tulle \& C. Phoenix (Eds.), Physical activity and sport in later life: Critical perspectives. London: Palgrave Macmillan. Public Health England (2014). Everybody active, every day: An evidence-based approach to physical activity. London: Public Health England.

Rejeski, W.J., \& Mihalko, S.L. (2001). Physical activity and quality of life in older adults. Journal of Gerontology: Series A, 56A(Si11), 23-35.

Ritchie, J., \& Spencer, L. (1994). Qualitative data analysis for applied policy research (pp. 173-194). In A. Bryman \& R.G. Burgess (Eds.), Analyzing qualitative data. London: Routledge.

Scholes, S., \& Mindell, J. (2013). Physical activity in adults. In R. Craig \& J. Mindell (Eds.), Health Survey for England 2012 (Vol 1, Ch 2, pp. 1-49). London: Health and Social Care Information Centre.

Spencer, L., Ritchie, J., O’Connor, W, Morrell, G., \& Ormston, R. (2013). Analysis in practice (pp. 295345). In J. Ritchie, J. Lewis, C. McNaugton Nicholls, \& R. Ormston (Eds.), Qualitative Research Practice: A Guide for Social Science Students and Researchers. London: Sage.

UK Department of Health, (2011). Start Active, Stay Active: A report on physical activity for health from the four home countries' Chief Medical Officers. London:

Venn, D., \& Strazdins, L. (2017). Your money or your time? How both types of scarcity matter to physical activity and healthy eating. Social Science \& Medicine, 172, 98-106. 